\title{
DURABLE WASH-RESISTANT ANTIMICROBIAL TREATMENT OF KNITTED FABRICS
}

\author{
Jolita Krisciunaite ${ }^{1}$, Brigita Kalendraite ${ }^{1}$, Lina Rageliené ${ }^{2}$, Evelina Merkelyte ${ }^{2}$, Daiva Mikucioniene $e^{1, *}$ \\ 1 Kaunas University of Technology, Faculty of Mechanical Engineering and Design, Department of Production Engineering, Studentu 56, LT-51424, \\ Kaunas, Lithuania \\ 2 Vytautas Magnus University, Faculty of Natural Sciences, Department of Biochemistry, Vileikos 8, LT-44404, Kaunas, Lithuania \\ ${ }^{*}$ Corresponding author. E-mail: daiva.mikucioniene@ktu.lt
}

\begin{abstract}
:
Antimicrobial finishing is increasingly used in textile products to increase their functionality. Antimicrobial properties became extremely important during the COVID-19 situation. The main problems faced by antimicrobial finishing are nontoxicity and durability (wash-resistance) of antibacterial activity. Also, it is important to determine whether the antimicrobial finishing changes comfort properties, such as air permeability. This paper deals with the durability of antimicrobial treatment, that is, resistance to washing, and effect on the structural changes that may have influence on the comfort properties, such as permeability to air. Knits of various raw compositions were antimicrobial-treated with the new commercial antimicrobial product, Si Bactericidal (Smart Inovation, Portugal). After the antimicrobial treatment, knitted specimens were washed 50 times and changes in their structural parameters, air permeability, and antimicrobial activity were measured. It was found that the mentioned antimicrobial treatment gives very good antimicrobial activity to the treated fabric and is wash-resistant and long-lasting. Also, it does not change dimensions and permeability to air of the treated fabrics with some exceptions of cotton-based knitted structures.
\end{abstract}

\section{Keywords:}

Antimicrobial treatment, antimicrobial activity, weft knit, air permeability, structural changes

\section{Introduction}

Nowadays, antimicrobial textile is one of the fastest growing areas of functional textiles. And it has become extremely important these days, when faced with this difficult global COVID-19 problem. Taking into account that textile products such as face masks must be frequently washed, antimicrobial finishing has to be durable, wash-resistant, and nontoxic. Most synthetic fibers, due to their hydrophobicity, are more resistant to microorganism growth than natural fibers. Natural fibers and various fiber combinations are prone to microorganism growth and bacteria colonization due to the textile surface characteristics. With increasing demand from consumers, the aim is to protect the fibers as well as the human body from microbial and bacterial growth [1]. The application of antimicrobial treatment to textiles can prevent bacterial growth. A suitable temperature, moisture, and receptive surface provide the perfect condition for the growth of microorganisms on textile that is in contact with the human skin. The growth of microorganisms on textiles inflicts a range of unwanted impacts not only on the textile itself, but also on the wearer: these include unpleasant odors, discoloration in the fabric, reduction of fabric mechanical strength, and so on [2].

Antimicrobial treatment is one of the most important finishes of the functional textile. There are several aspects to the antimicrobial treatment of textile. The first aspect is to protect the textile material from damage caused by microorganisms; the other aspect is protection of the user from growth of pathogenic microorganisms. Almost all antimicrobial agents used for finishing of commercial textiles, for example, silver, zinc oxide, triclosan, copper compounds, and so on, are biocides. Due to their importance, the number of different antimicrobial agents for textile application has dramatically increased. These antimicrobial agents differ in their chemical structure, effectiveness, method of application, and influence on humans, the environment, as well as on cost [2-4]. First, the antimicrobial treatment should be effective against a broad spectrum of bacterial and fungal species, but at the same time not cause toxicity, allergy, or irritation to the user. Second, the finishing should be durable to washing, dry cleaning, and hot pressing, and this is the greatest challenge as textile products are subjected to repeated washing during their lifetime. Also, the finishing should not have a negative effect on the quality or appearance of the textile. And finally, the finishing should be compatible with other textile chemical processes such as dyeing or printing, be cost-effective, and not harm the environment [2].

The antimicrobial agents can be applied to the textile substrate by exhaust, pad-dry-cure, coating, spray, and foam techniques. Antimicrobial agents are usually applied the finishing stages of textile production, while in some cases biocide can be incorporated into synthetic fibers during extrusion [5-9]. A large number of studies were conducted to investigate the resistance of a varied spectrum of antimicrobial materials on textile. Many researchers have analyzed the antimicrobial activity after antimicrobial treatment of fabrics made of cotton, wool, polyamide, polyester yarns, and their various combinations 
[10-13]. It was found that antimicrobial-treated knits with the same fiber composition and very similar total linear density of yarns but with different number of folded yarns in the structure have different antimicrobial activities, because a higher number of folded yarns in the knitted loop has a larger surface area and, therefore, a larger antimicrobial acting area [14]. The antimicrobial activity of the plaited knits, in which yarns of different raw material are distributed on opposite surfaces, depends on the construction of yarns, too [14-16].

The application of antimicrobial finish has to prevent bacterial growth on the textile, however, it may change the fabrics or products physical and/or aesthetic properties, like the texture or surface characteristics such as density or porosity, especially if wet treatment processes are used. It is well known that the surface porosity and loop density in knitted fabrics have a direct influence on the air permeability of the fabric. Air permeability is considered to be one of the most important features of clothing comfort which ensures physiological comfort [15-18].

The aim of the present work was to determine the influence of antimicrobial textile finishing using "Si Bactericidal" on durability (wash-resistance) of the antimicrobial activity and on changes of structural parameters and air permeability of the treated knitted fabrics.

\section{Materials and methods}

Seven variants of knitted fabrics were produced for antimicrobial treatment and investigated in this research. All the experimental samples were knitted in a rib $1 \times 1$ pattern on the same flat $10 \mathrm{E}$ gauge double-needle-bed weft knitting machine CMS530 (Stoll, Germany). The samples were knitted using yarns of different raw materials: pure woollen, cotton and acrylic yarns, and blended wool/acrylic yarns (with three different percentages of the wool and acrylic fibers in the yarn) and cotton/acrylic blended yarns. Structure parameters of the knits were analyzed according to the Standard LST EN 14971:2006. The main structural parameters of these knitted fabrics are presented in Table 1.

All the experiments were carried out in the standard atmosphere according to Standard ISO 139 , that is, $20 \pm 2^{\circ} \mathrm{C}$ temperature and $65 \pm 4 \%$ humidity.

All knitted samples were treated by "Si Bactericidal Textile Finish," a technology proposed by the Portuguese company, Smart Inovation, Lda. This technology has advantages such as easy application and nontoxicity. It does not use heavy metals, silver, or other toxic substances and is eco-friendly. The active antimicrobial agent is Benzalkonium chloride (BKC). $\mathrm{BKC}$ was covered on the textile materials using the method of wet impregnation. The main conditions of the antimicrobial treatment were as follows: aqueous solution of $30^{\circ} \mathrm{C}$ was prepared by inserting the components in the bath in the following order and ratio: $41 \mathrm{ml} / \mathrm{l}$ of "Si Bactericidal" and $7 \mathrm{ml} / \mathrm{l}$ of auxiliary Smart Fix, pH of the bath at 6-6.5, the absorption rate at $70 \%$, and duration of the treatment at $15 \mathrm{~min}$. After that, drying for $15 \mathrm{~min}$ at $120^{\circ} \mathrm{C}$ was applied.

After the antimicrobial treatment, the samples were washed 50 times, and after each washing and drying cycle their structural parameters, antimicrobial activity, and permeability to air were measured.

The washing procedure was performed according to the standard ISO 6330:2012. The samples were washed for $15 \pm 0.5 \mathrm{~min}$ in $40 \pm 2{ }^{\circ} \mathrm{C}$ temperature washing solution with $3 \mathrm{~g} / \mathrm{l}$ washing powder concentration. After the main washing, the samples were rinsed thrice in $20 \pm 2{ }^{\circ} \mathrm{C}$ temperature. The duration of each rinse was $1 \pm 0.1 \mathrm{~min}$. The rinsed samples were spin-dried (frequency of revolution 1,000 min-1) for $1 \pm 0.1 \mathrm{~min}$ and dried for $24 \mathrm{~h}$ on a smooth surface in the standard atmosphere conditions.

Table 1. Main structural parameters of knitted fabrics.

\begin{tabular}{|c|c|c|c|c|c|c|c|}
\hline $\begin{array}{l}\text { Sample } \\
\text { code }\end{array}$ & $\begin{array}{c}\text { Raw composition and yarn } \\
\text { linear density }\end{array}$ & $\begin{array}{c}\text { Wale } \\
\text { density } \\
\left(\mathrm{cm}^{-1}\right)\end{array}$ & $\begin{array}{c}\text { Course } \\
\text { density } \\
\left(\mathrm{cm}^{-1}\right)\end{array}$ & $\begin{array}{c}\text { Wale } \\
\text { spacing } \\
(\mathrm{mm})\end{array}$ & $\begin{array}{c}\text { Course } \\
\text { spacing } \\
(\mathrm{mm})\end{array}$ & $\begin{array}{c}\text { Loop } \\
\text { length } \\
\text { (mm) }\end{array}$ & $\begin{array}{c}\text { Area } \\
\text { density }(g / \\
\left.m^{2}\right)\end{array}$ \\
\hline$A$ & $\begin{array}{c}100 \% \text { woollen yarns, } 38 \text { tex } \\
x 2\end{array}$ & 36.0 & 10.5 & 2.77 & 0.97 & 7.39 & 417.7 \\
\hline$B$ & $\begin{array}{c}70 \% \text { woollen } / 30 \% \text { acrylic } \\
\text { yarns, } 40 \text { tex x } 2\end{array}$ & 34.0 & 10.0 & 2.92 & 0.98 & 7.67 & 431.0 \\
\hline $\mathrm{C}$ & $\begin{array}{c}50 \% \text { woollen } / 50 \% \text { acrylic } \\
\text { yarns, } 40 \text { tex x } 2\end{array}$ & 34.0 & 10.0 & 2.92 & 0.99 & 7.68 & 427.4 \\
\hline$D$ & $\begin{array}{c}30 \% \text { woollen } / 70 \% \text { acrylic } \\
\text { yarns, } 31 \text { tex x } 2\end{array}$ & 37.0 & 11.0 & 2.68 & 0.89 & 6.96 & 360.5 \\
\hline$E$ & $100 \%$ acrylic yarns, 31 tex $x 2$ & 35.0 & 11.5 & 3.21 & 0.97 & 7.95 & 316.8 \\
\hline $\mathrm{F}$ & $\begin{array}{c}50 \% \text { cotton } / 50 \% \text { acrylic, } 33 \\
\text { tex } x 2\end{array}$ & 34.0 & 12.0 & 2.92 & 0.83 & 7.18 & 392.2 \\
\hline G & $100 \%$ cotton yarns, 29 tex $x 2$ & 31.0 & 10.5 & 2.84 & 0.85 & 6.99 & 333.9 \\
\hline
\end{tabular}


The antimicrobial efficiency of samples was tested with the Gram-negative E. coli (KMY1T) and the Gram-positive S. aureus (ATCC25923) bacteria. The qualitative evaluation of antimicrobial efficiency of the treated knitted samples was carried out in accordance with EN ISO 20645:2004 (Agar diffusion plate test). The plates were incubated for $18 \mathrm{~h}$ at $37^{\circ} \mathrm{C}$ and afterwards the width of the inhibition zone was calculated as follows:

$H=\frac{D-d}{2} \quad ;$

where $H$ is the inhibition zone in $\mathrm{mm}, D$ is the total diameter of sample and inhibition zone in $\mathrm{mm}$, and $d$ is the diameter of sample in millimeters.

Three tests of antimicrobial activity were performed for each sample variant. The evaluation criteria of the antimicrobial effect are presented in Table 2.

The air permeability test of the knitted fabrics was conducted according to Standard EN ISO 9237:1997, using a head area of $5 \mathrm{~cm}^{2}$ and pressure difference of $100 \mathrm{~Pa}$. 10 tests were performed for each sample variant. The air permeability was calculated according to the following equation:

$R=\frac{D}{A} \cdot 167$

where $R$ is the air permeability in $\mathrm{dm}^{3} /\left(\mathrm{m}^{2} \mathrm{~s}\right) ; D$ is the average of air flow rate, $\mathrm{dm}^{3} / \mathrm{min}$; and $A$ is the operative area of the sample equal to $5 \mathrm{~cm}^{2}$.

\section{Experimental results and discussion}

\subsection{Antimicrobial activity}

Growth of Gram-negative E. coli and Gram-positive S. aureus bacteria on specimens knitted from different raw materials $(100 \%$ woollen yarns, blended woollen/acrylic yarns in different percentage, $100 \%$ acrylic, $100 \%$ cotton yarns and blended cotton/acrylic yarns) was tested after antimicrobial treatment and after different number of washing cycles $(1,5,10,20,30$, $50)$. The results were compared with the growth of mentioned bacteria on the same specimens before antimicrobial treatment. The results of the measured antimicrobial activity and size of the inhibition zone are presented in Table 3 and some variants of experiments are illustrated in Figures 1-4.

All antimicrobial treated knitted fabrics showed very good antimicrobial activity. Analysis of the test results, presented in Table 2 and illustrated in Figures 1-4, indicate that the antimicrobial activity of the treated knits was higher against Gram-positive (S. aureus) bacteria than Gram-negative (E. coli) bacteria. There are some differences in antimicrobial activity depending on the raw composition of knitted specimens; however, after the antimicrobial treatment, all the fabrics demonstrated good effect with a 4- $\mathrm{mm}$ inhibition zone for $S$. aureus and a 2-2.5 mm inhibition zone for $E$. coli bacteria. It means that strong bonds between antibacterial agent BKC and every investigated raw material were formed. But the main issue in antimicrobial finishing is to obtain antimicrobial activity resistant to washing. Thus, this antimicrobial finishing can be recommended for knitted fabrics with different raw compositions. As it can be seen from the presented results, good antimicrobial activity (with some inhibition zone) against Gram-negative $E$. coli bacteria remains for at least 10 washing cycles. After 20 washing cycles, it still remains, though limited. The results against Gram-positive S. aureus bacteria are even better. Good antimicrobial effect remains for at least 20

Table 2. Evaluation criteria of antimicrobial effect.

\begin{tabular}{|c|c|c|c|}
\hline $\begin{array}{l}\text { Inhibition zone } \\
\text { (mm) }\end{array}$ & Growth $^{a}$ & Description & Assessment \\
\hline \multicolumn{4}{|l|}{ Mean value } \\
\hline $\begin{array}{c}>1 \\
1-0 \\
0\end{array}$ & $\begin{array}{l}\text { None } \\
\text { None } \\
\text { None }\end{array}$ & $\begin{array}{l}\text { Inhibition zone exceeding } 1 \mathrm{~mm} \text {, no growth } \\
\text { Inhibition zone up to } 1 \mathrm{~mm} \text {, no growth } \\
\text { No inhibition zone, no growth }\end{array}$ & Good effect \\
\hline 0 & Slight & $\begin{array}{l}\text { No inhibition zone, only some restricted colonies, growth nearly totally } \\
\text { suppressed }^{d}\end{array}$ & Limit of efficacy \\
\hline $\begin{array}{l}0 \\
0\end{array}$ & $\begin{array}{c}\text { Moderate } \\
\text { Heavy }\end{array}$ & $\begin{array}{c}\text { No inhibition zone compared with the control growth reduced to halfe } \\
\text { No inhibition zone compared with the control no growth reduction or } \\
\text { only slightly reduced growth }\end{array}$ & $\begin{array}{c}\text { Insufficient } \\
\text { effect }\end{array}$ \\
\hline
\end{tabular}

aThe growth of bacteria in the nutrient medium under the specimen.

${ }^{\mathrm{b}}$ The extent of inhibition shall only partly be taken into account. A large inhibition zone may indicate certain reserves of active substances or a weak fixation of a product on the substrate.

${ }^{\mathrm{c}}$ The absence of growth, even without an inhibition zone, may be regarded as a good effect, as the formation of such a zone may have been prevented by a low diffusibility of the active substance.

d"As good as no growth" indicates the limits of efficacy.

eReduced density of bacterial growth means either the number of colonies or the colony diameter. 
Table 3. Antimicrobial activity of tested knitted fabrics.

\begin{tabular}{|c|c|c|c|}
\hline \multirow{2}{*}{\multicolumn{2}{|c|}{ Specimen }} & \multicolumn{2}{|c|}{ Inhibition zone, $\mathrm{mm}$, and antimicrobial efficacy } \\
\hline & & Staphylococcus aureus & Escherichia coli \\
\hline Before antimicrobial treatment & $\begin{array}{c}\text { A-100\% woollen yarns } \\
\text { B-70\% woollen } / 30 \% \text { acrylic yarns } \\
\text { C-50\% woollen } / 50 \% \text { acrylic yarns } \\
\text { D-30\% woollen } / 70 \% \text { acrylic yarns } \\
\text { E- } 100 \% \text { acrylic } \\
\text { F-50\% cotton } / 50 \% \text { acrylic yarns } \\
\text { G- } 100 \% \text { cotton yarns }\end{array}$ & 0 (no efficacy) & 0 (no efficacy) \\
\hline \multirow[t]{7}{*}{ After antimicrobial treatment } & A-100\% woollen yarns & 4 (good effect) & 2.5 (good effect) \\
\hline & B-70\% woollen $/ 30 \%$ acrylic yarns & 4 (good effect) & 2.5 (good effect) \\
\hline & C- $50 \%$ woollen $/ 50 \%$ acrylic yarns & 4 (good effect) & 2 (good effect) \\
\hline & D-30\% woollen $/ 70 \%$ acrylic yarns & 4 (good effect) & 2 (good effect) \\
\hline & E-100\% acrylic & 4 (good effect) & 2 (good effect) \\
\hline & $\mathrm{F}-50 \%$ cotton $/ 50 \%$ acrylic yarns & 4 (good effect) & 2 (good effect) \\
\hline & G-100\% cotton yarns & 4 (good effect) & 2.5 (good effect) \\
\hline \multirow[t]{7}{*}{ After first washing cycle } & A-100\% woollen yarns & 3 (good effect) & 1.5 (good effect) \\
\hline & B-70\% woollen $/ 30 \%$ acrylic yarns & 3 (good effect) & 1.5 (good effect) \\
\hline & C- $50 \%$ woollen $/ 50 \%$ acrylic yarns & 3 (good effect) & 1.5 (good effect) \\
\hline & D-30\% woollen $/ 70 \%$ acrylic yarns & 3 (good effect) & 1.5 (good effect) \\
\hline & E-100\% acrylic & 2.5 (good effect) & 1.5 (good effect) \\
\hline & $\mathrm{F}-50 \%$ cotton $/ 50 \%$ acrylic yarns & 2.5 (good effect) & 1 (good effect) \\
\hline & G-100\% cotton yarns & 2.5 (good effect) & 1 (good effect) \\
\hline \multirow[t]{7}{*}{ After 5 washing cycles } & A-100\% woollen yarns & 2.5 (good effect) & 1.5 (good effect) \\
\hline & B-70\% woollen $/ 30 \%$ acrylic yarns & 2.5 (good effect) & 1 (good effect) \\
\hline & C- $50 \%$ woollen $/ 50 \%$ acrylic yarns & 2.5 (good effect) & 1 (good effect) \\
\hline & D-30\% woollen $/ 70 \%$ acrylic yarns & 2 (good effect) & 1 (good effect) \\
\hline & E-100\% acrylic & 2 (good effect) & 1 (good effect) \\
\hline & F- $50 \%$ cotton $/ 50 \%$ acrylic yarns & 2 (good effect) & 1 (good effect) \\
\hline & G-100\% cotton yarns & 2 (good effect) & 1 (good effect) \\
\hline \multirow[t]{7}{*}{ After 10 washing cycles } & A-100\% woollen yarns & 1.5 (good effect) & 1 (good effect) \\
\hline & B-70\% woollen $/ 30 \%$ acrylic yarns & 1.5 (good effect) & 1 (good effect) \\
\hline & C- $50 \%$ woollen $/ 50 \%$ acrylic yarns & 1.5 (good effect) & 1 (good effect) \\
\hline & D-30\% woollen $/ 70 \%$ acrylic yarns & 1.5 (good effect) & 1 (good effect) \\
\hline & E-100\% acrylic & 1.5 (good effect) & 0 (limited efficacy) \\
\hline & $\mathrm{F}-50 \%$ cotton $/ 50 \%$ acrylic yarns & 1.5 (good effect) & 0 (limited efficacy) \\
\hline & G-100\% cotton yarns & 1.5 (good effect) & 1 (good effect) \\
\hline \multirow[t]{7}{*}{ After 20 washing cycles } & A-100\% woollen yarns & 1 (good effect) & 0 (limited efficacy) \\
\hline & B-70\% woollen $/ 30 \%$ acrylic yarns & 1 (good effect) & 0 (limited efficacy) \\
\hline & C- $50 \%$ woollen $/ 50 \%$ acrylic yarns & 1 (good effect) & 0 (limited efficacy) \\
\hline & D-30\% woollen $/ 70 \%$ acrylic yarns & 1 (good effect) & 0 (limited efficacy) \\
\hline & E- $100 \%$ acrylic & 1 (good effect) & 0 (insufficient effect) \\
\hline & $\mathrm{F}-50 \%$ cotton $/ 50 \%$ acrylic yarns & 1 (good effect) & 0 (limited efficacy) \\
\hline & G-100\% cotton yarns & 1 (good effect) & 0 (limited efficacy) \\
\hline
\end{tabular}


Table 3 Antimicrobial activity of tested knitted fabrics.

\begin{tabular}{|c|c|c|c|}
\hline \multirow{2}{*}{\multicolumn{2}{|c|}{ Specimen }} & \multicolumn{2}{|c|}{ Inhibition zone, $\mathrm{mm}$, and antimicrobial efficacy } \\
\hline & & Staphylococcus aureus & Escherichia coli \\
\hline \multirow[t]{7}{*}{ After 30 washing cycles } & A-100\% woollen yarns & \multirow{7}{*}{0 (limited efficacy) } & \multirow{7}{*}{0 (insufficient efficacy) } \\
\hline & B-70\% woollen $/ 30 \%$ acrylic yarns & & \\
\hline & C- $50 \%$ woollen $/ 50 \%$ acrylic yarns & & \\
\hline & D-30\% woollen $/ 70 \%$ acrylic yarns & & \\
\hline & E-100\%acrylic & & \\
\hline & $\mathrm{F}-50 \%$ cotton $/ 50 \%$ acrylic yarns & & \\
\hline & G-100\%cotton yarns & & \\
\hline \multirow[t]{7}{*}{ After 50 washing cycles } & A-100\% woollen yarns & \multirow{7}{*}{0 (insufficient efficacy) } & \multirow{7}{*}{0 (insufficient efficacy) } \\
\hline & B-70\% woollen $/ 30 \%$ acrylic yarns & & \\
\hline & C- $50 \%$ woollen $/ 50 \%$ acrylic yarns & & \\
\hline & D_-30\% woollen $/ 70 \%$ acrylic yarns & & \\
\hline & E-100\%acrylic & & \\
\hline & $\mathrm{F}-50 \%$ cotton $/ 50 \%$ acrylic yarns & & \\
\hline & G-100\%cotton yarns & & \\
\hline
\end{tabular}

a)

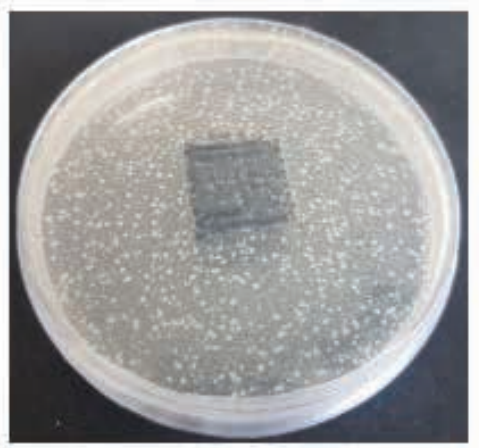

b)

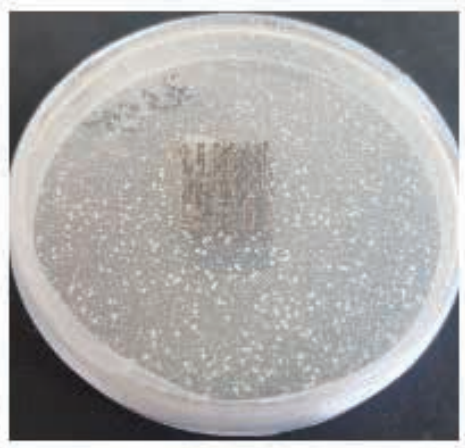

c)

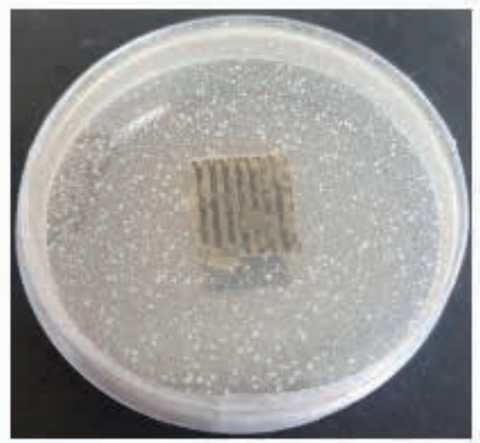

Figure 1. Growth of Gram-negative E. coli bacteria on the surface of untreated knits from (a) $100 \%$ woollen, (b) blended $50 \%$ woollen/50\% acrylic, and (c) $100 \%$ acrylic yarns).

a)

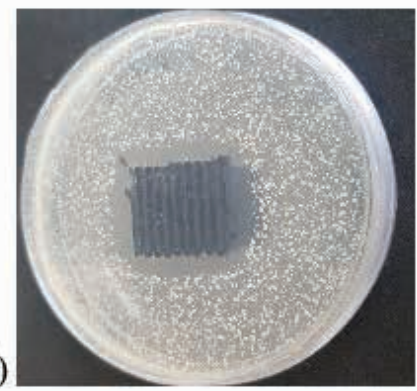

$\underline{\text { E. coli }}$

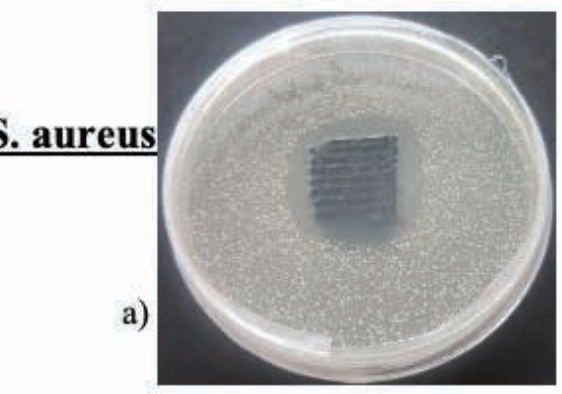

b)

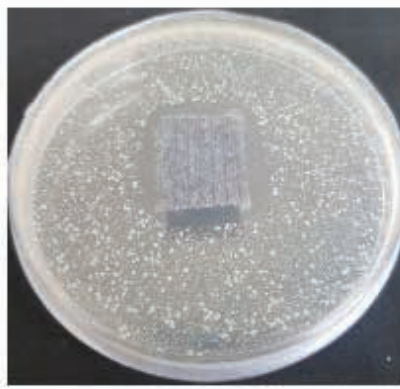

c)

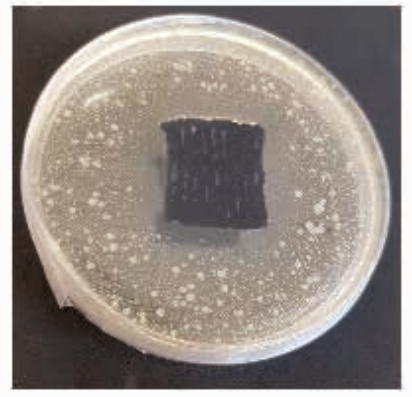

b)

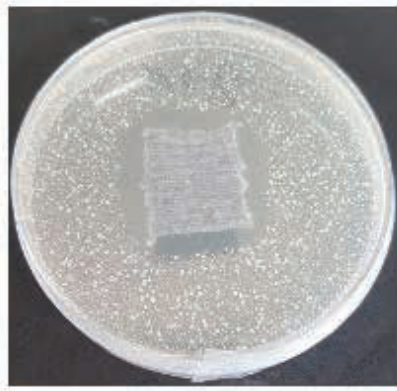

c)

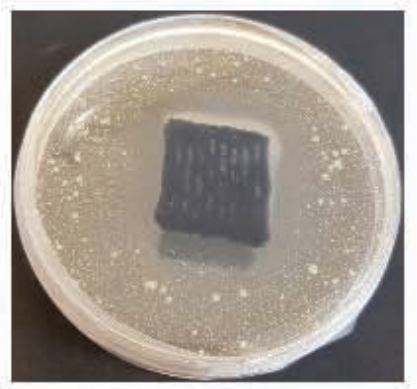

Figure 2. Growth of Gram-negative E. coli and Gram-positive S. aureus bacteria on the surface of knits after antimicrobial treatment from (a) $100 \%$ woollen, (b) blended $50 \%$ woollen $/ 50 \%$ acrylic, and (c) $100 \%$ acrylic yarns. 
a)

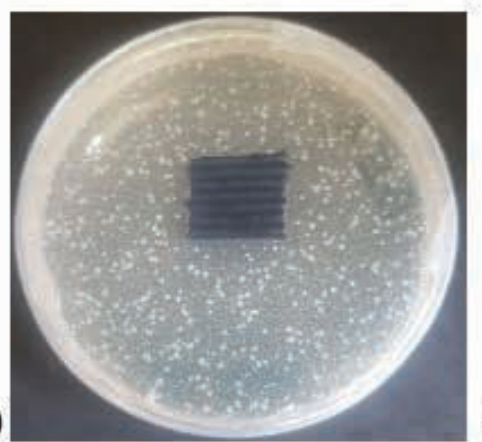

b)

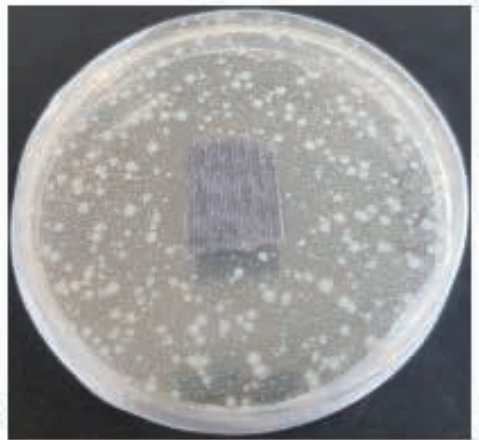

c)

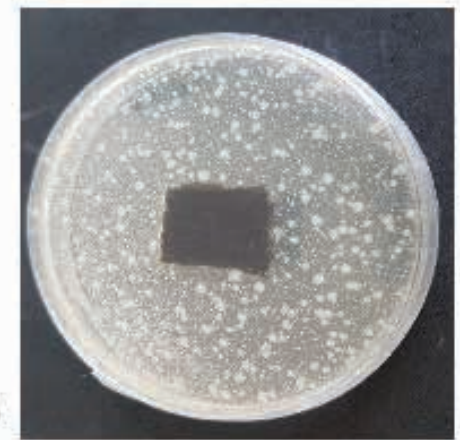

b)

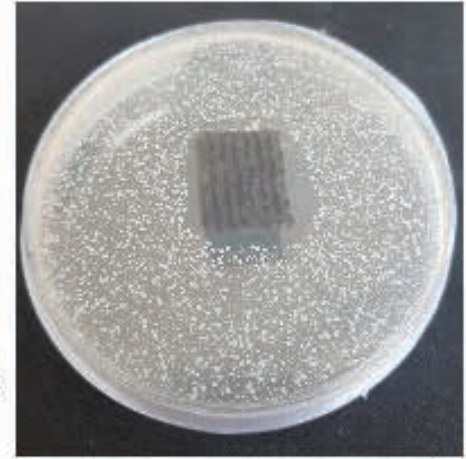

c)

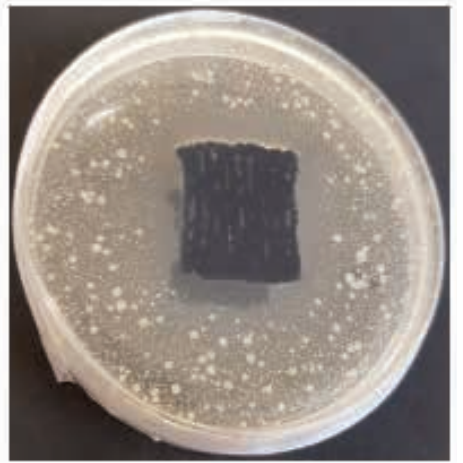

Figure 3. Growth of Gram-negative E. coli and Gram-positive S. aureus bacteria on the surface of knits after 5 washing cycles from (a) $100 \%$ woollen, (b) blended $50 \%$ woollen $/ 50 \%$ acrylic, and (c) $100 \%$ acrylic yarns.

a)

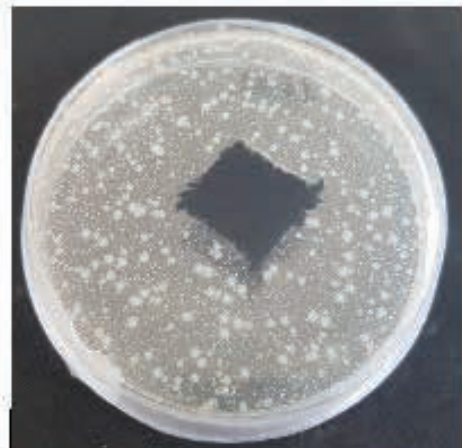

b)

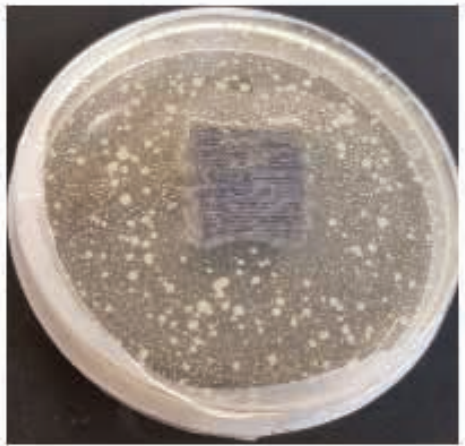

c)
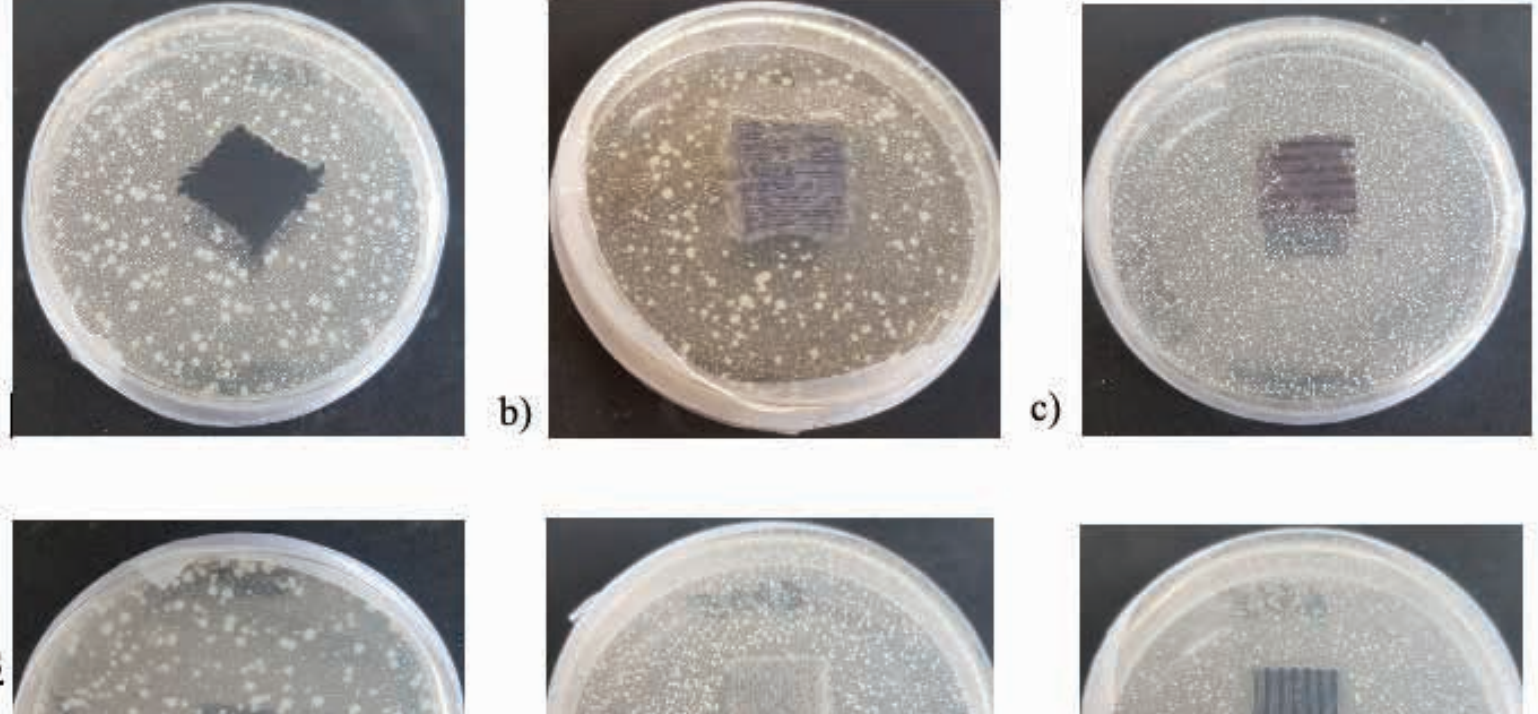

a)

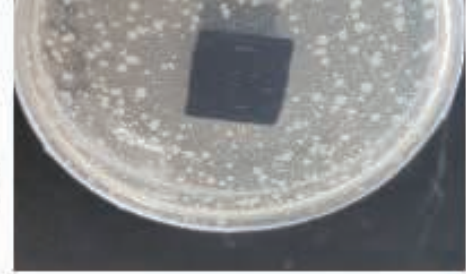

b)

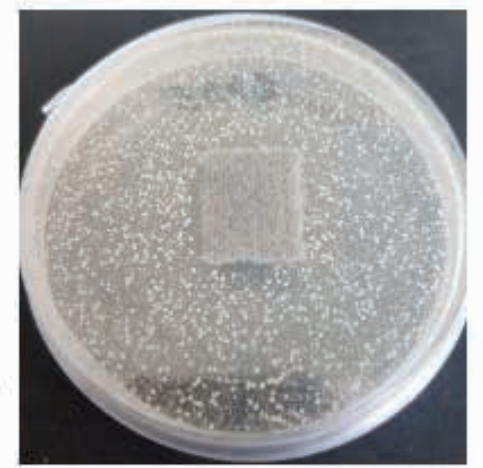

c)

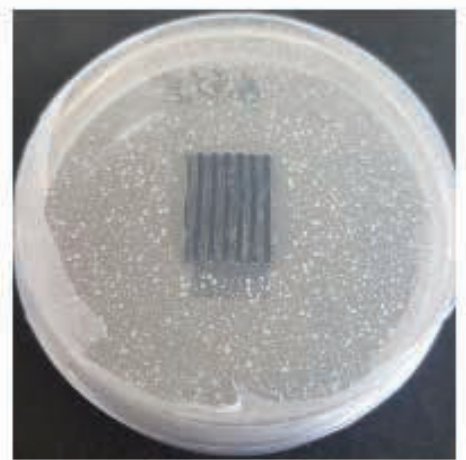

Figure 4. Growth of Gram-negative E. coli and Gram-positive S. aureus bacteria on the surface of knits after 20 washing cycles from (a) $100 \%$ woollen, (b) blended $50 \%$ woollen $/ 50 \%$ acrylic, and (c) $100 \%$ acrylic yarns.

washing cycles. After 30 washing cycles, the treated fabrics have some limited antimicrobial activity, that is, an inhibition zone does not form around the specimen but there is no growth of bacteria on and under the sample. And even after 50 washing cycles, slightly reduced growth of bacteria on and under the specimens can be checked. These results are exceptionally good and promising, especially taking into account the fact that this antimicrobial finishing is very easy applicable and compatible with other wet finishing operations and gives very good antimicrobial durability. Also, it can be applied to fabrics knitted from yarns of different raw materials (natural, synthetic, or blended), which can be used for different purposes, including 
washable face masks. Long-term, washing-resistant and nontoxic antimicrobial activity is especially important for textile face masks.

\subsection{Influence of antimicrobial treatment and washing on structural parameters}

Fabric shrinkage is a serious problem for weft knitted fabrics and this problem is investigated by numerous researchers. It is well known that dimensions of most weft knitted fabrics, especially those knitted from natural fiber yarns, are sensitive to wet treatments. Wet processing creates the ideal conditions for structural and dimensional changes in knitted fabrics. Therefore, it is important to know how much antimicrobial treatment (wet impregnation) will change the structural properties of investigated knitted structures, such as course and wale densities that have a direct influence on the dimensions and porosity of fabrics.

Course and wale densities of the tested fabrics were counted in the length and crosswise directions of the knitted samples before and after antimicrobial treatment, as well as after repeated washing and drying cycles in order to investigate the influence of wet treatment on the possible structural changes, such as change in the loop geometry and loops density in the wale and course directions. A higher than $\pm 3 \%$ change in dimensions after washing and drying is undesirable; however, this is usually characteristic for weft knits especially made of cellulose-based yarns.

The obtained results are presented in Figures 5 and 6 . As it can be seen from the presented results, the most resistant to dimensional changes (especially in longitudinal direction) after wet antimicrobial treatment and washing is the fabric knitted from pure synthetic ( $100 \%$ acrylic) yarn; also good dimensional stability was shown by knits made from pure woollen yarns and their blend with acrylic yarns (in different percentages). Knits made from blended (in various percentages) woollen/ acrylic yarns slightly shrunk in the transversal direction and got elongated in the longitudinal direction. These dimensional changes are quite small but higher than that of knits made of pure woollen or acrylic yarns. The highest dimensional changes (especially in transversal direction) were established for pure cotton and cotton-based knits. Such tendency was also proved by other researchers [19, 20]. However, it was noticed that the highest dimensional changes in cotton-based knitted fabrics are not after the antimicrobial treatment but after the first washing cycle. This is very important, as it shows that the antimicrobial treatment is not harmful for knitted fabrics in terms of dimensional changes. The dimensional changes after the repeated washing cycles varied in the ranges of error.

\subsection{Influence of antimicrobial treatment and washing on air permeability}

It is well known that air permeability directly correlates with textile porosity, while the porosity of knitted fabrics is interrelated to the loop density. Thus, in order to investigate the influence of wet antimicrobial treatment on the air permeability of the knits, air permeability tests were performed according to the methodology mentioned above.

As it was expected, the results of the air permeability test of untreated knitted fabrics are related to the loop length, loop density, yarn linear density, and row material (hairiness of the yarn surface) of knitted fabrics. It was found that the highest permeability to air has the pure acrylic knitted fabric (see in Figure 7). This result was influenced by the lower yarn linear

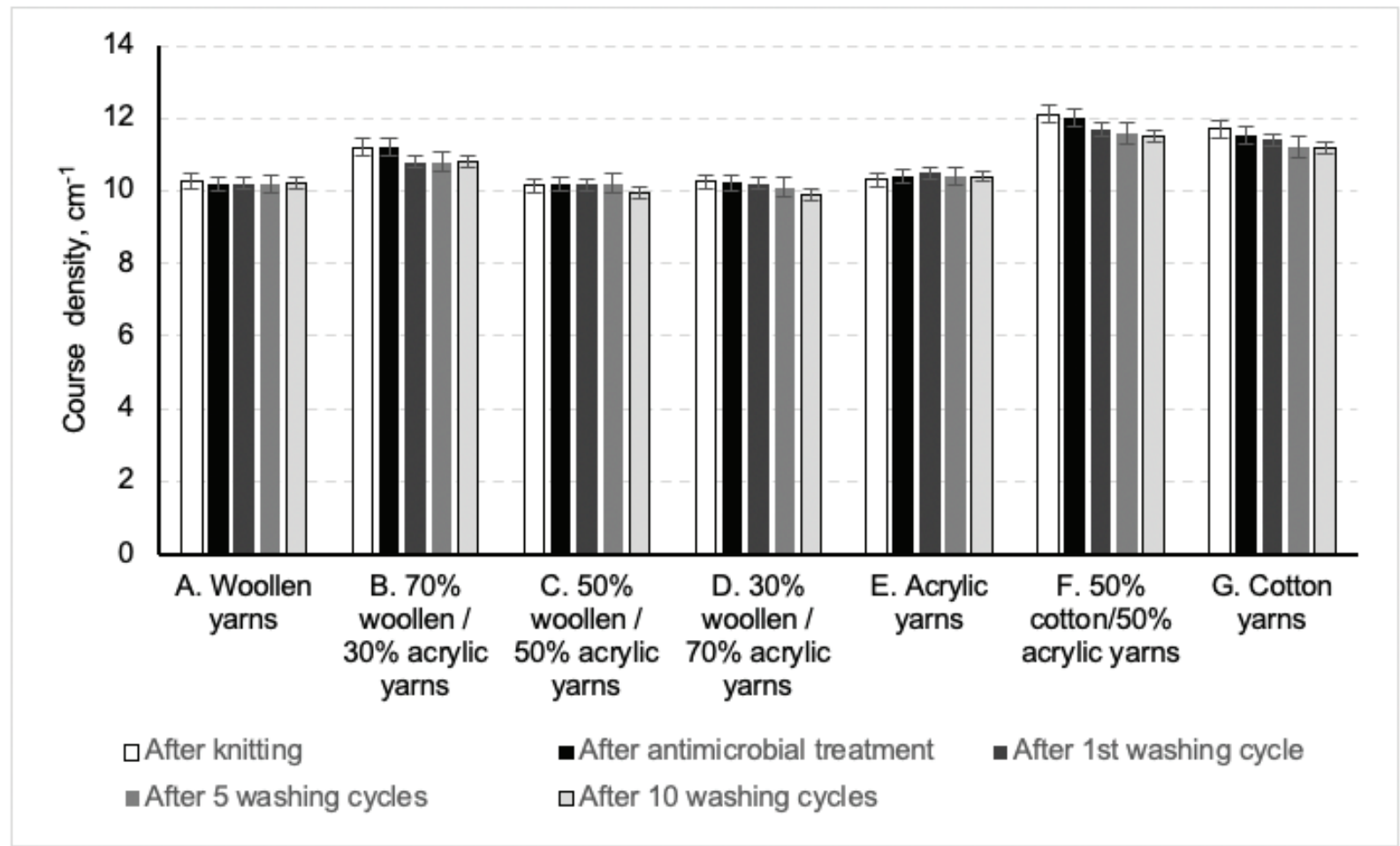

Figure 5. Course density of tested knitted fabrics after different washing cycles. 
density (31 tex x2) and higher loop length $(7.95 \mathrm{~mm}$ ) on one hand, and the lower hairiness of the yarn surface on the other hand. A comparison of woollen and wool-blended knitted fabrics shows that they have very similar air permeability. The lowest air permeability was observed for cotton and cotton-blended fabrics, especially after the wet treatment.
As it can be seen from the results presented in Figure 7, the antimicrobial treatment of woollen, wool-blended, and acrylic knitted fabrics using Si Bactericidal does not have a significant influence on the air permeability; the changes are in the ranges of error. After antimicrobial treatment, air permeability decreased more significantly only for cotton and cotton/acrylic blended fabrics (it was obtained $116.7 \mathrm{dm}^{3} /\left(\mathrm{m}^{2} \mathrm{~s}\right)$ and $66.7 \mathrm{dm}^{3} /$ $\left(m^{2} s\right)$ decrease, respectively).

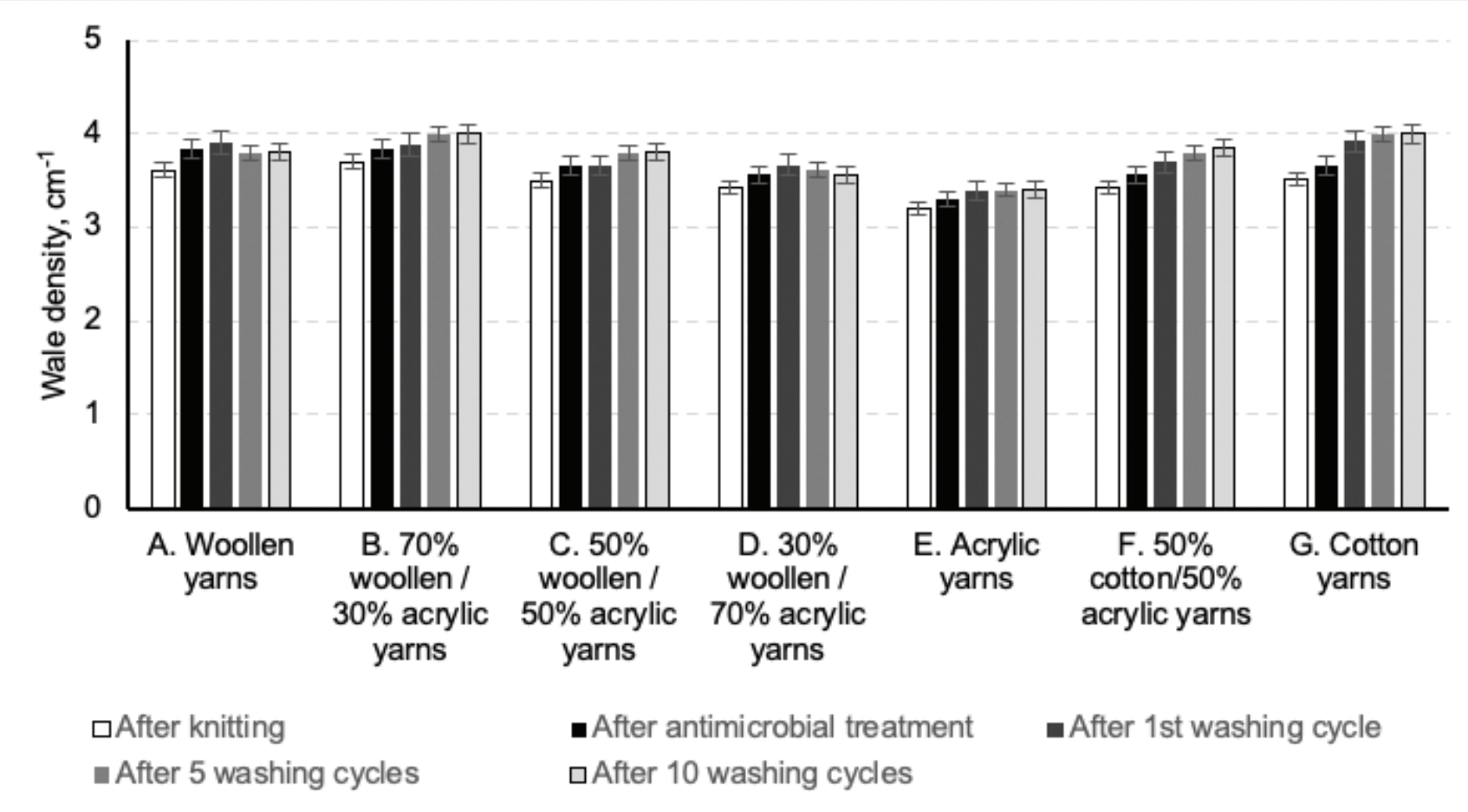

Figure 6. Wale density of tested knitted fabrics after different washing cycles.

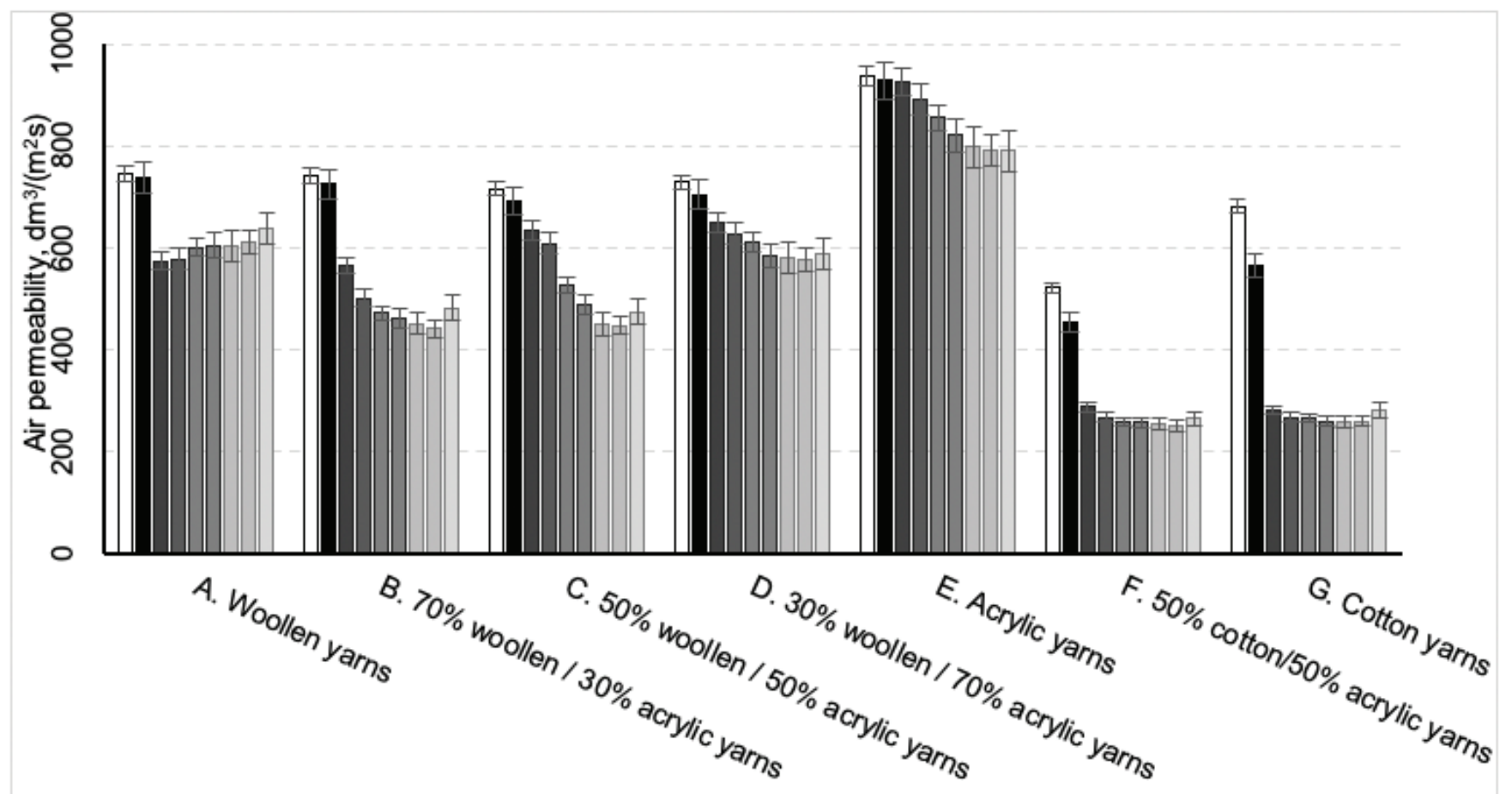

Figure 7. Air permeability of tested knitted fabrics before wet treatment, after antimicrobial treatment, and after repeated washing and drying. 
The highest drop in air permeability was observed after the first washing and drying cycle, especially for the pure cotton and woollen knits as well as for blended $50 \%$ cotton $/ 50 \%$ acrylic and $70 \%$ woollen $/ 30 \%$ acrylic knitted fabrics. This was expected beforehand, as it is well known the tendency of cotton and woollen weft knitted fabrics to shrink and tighten during the wet treatment (in our case, during washing) [15, 19, 20]. After the first washing and drying cycle, air permeability fell by more than $400 \mathrm{dm}^{3} /\left(\mathrm{m}^{2} \mathrm{~s}\right)$ for pure cotton fabric and by more than $230 \mathrm{dm}^{3} /\left(\mathrm{m}^{2} \mathrm{~s}\right)$ for blended cotton/acrylic knitted fabric, while for pure acrylic fabric the air permeability decreased by less than $10 \mathrm{dm}^{3} /\left(\mathrm{m}^{2} \mathrm{~s}\right)$. The behavior of wool/acrylic blended fabrics obviously depends on the percentage composition, that is, the proportion of the woollen and acrylic fibers in the blended yarns. After repeated washing cycles, the air permeability gradually and slightly changed (for woollen, acrylic and blended woollen/acrylic fabrics) or varied in the ranges of error (for cotton and blended cotton/acrylic knitted fabrics). However, after approximately 50 washing cycles, the air permeability of all investigated fabrics starts to increase (with the exception of $100 \%$ acrylic knit), and this is because of the loss of fibers from the knitted structure.

The main conclusion of this research is that antimicrobial treatment does not have or has a conditionally low impact on dimensional changes as well as on decrease of air permeability of the treated knitted fabrics. This means that the used antimicrobial "Si Bactericidal" treatment does not worsen the main comfort properties, gives good antimicrobial activity and resistance to washing, is easy to apply, and there is a possibility to combine it with other wet-finishing processes. Such antimicrobial-treated knitted fabrics can be used for different purposes such as washable face masks, clothing for active leisure and sport, so on.

\section{Conclusion}

After the antimicrobial treatment of seven variants of knits with different raw composition by using the easy applicable method of wet impregnation in aqueous solution with "Si Bactericidal" and repeated washing and drying cycles, it was found that this treatment gives very good antimicrobial activity against the Gram-negative E. coli (KMY1T) and the Gram-positive $S$. aureus (ATCC25923) bacteria as well as very good resistance of this activity to washing. Good antimicrobial activity with the inhibition zone against $E$. coli bacteria remains after at least 10 washing cycles and against $S$. aureus bacteria after at least 20 washing cycles of all investigated raw compositions of knits: $100 \%$ woollen, $100 \%$ acrylic, different percentages of blended woollen/acrylic $(70 \% / 30 \%, 50 \% / 50 \%, 30 \% / 70 \%$, respectively), $100 \%$ cotton, and $50 \%$ cotton $/ 50 \%$ acrylic. And even after 30 washing cycles, the treated fabrics have some limited antimicrobial activity. It is a very promising antimicrobial treatment of textiles, especially taking into account its possible compatibility with other finishing processes (dyeing, printing, laundering, etc.), the application to different raw materials, and very good durability during washing.
The antimicrobial treatment does not significantly change dimensions nor permeability to air of the treated knitted fabrics, while the obtained changes were in the ranges of error, with the only exception for air permeability of cotton and cottonblended fabrics. This is a very positive conclusion because the treatment used to obtain additional functionality cannot worsen the other properties of the fabric.

\section{ACKNOWLEDGMENTS}

This work was partially supported by the Project S-COV-20-7 "Improvement of protective masks and adaptation of production technologies to Lithuanian textile sector in case of possible extreme conditions (PROTEX)" financed by the Research Council of Lithuania.

\section{References}

[1] Tawiah, B., Badoe, W., Fu, S. (2016). Advances in the development of antimicrobial agents for textiles: The quest for natural products. Review. Fibres \& Textiles in Eastern Europe, 24(3), 136-149.

[2] Gao, Y., Cranston, R. (2008). Recent advances in antimicrobial treatment of textiles. Textile Research Journal, 78(1), 60-72.

[3] Mahltig, B., Haufe, H., Böttcher, H. (2005). Functionalization of textiles by inorganic sol-gel coatings. Journal of Materials Chemistry, 41(15), 4385-4398.

[4] Mikucioniene, D., Milasius, R., Daugelavicius, R., Rageliene, L., Venslauskaite, N., Ragaisiene, A., Rukuiziene, Z. (2016). Preliminary investigation into the antimicrobial activity of an electrospun polyamide nanofibrous web with micro particles of Baltic amber. Fibres \& Textiles in Eastern Europe, 24(5), 34-37.

[5] Simončič, B., Tomšič, B. (2010). Structure of novel antimicrobial agents for textile $-A$ review. Textile Research Journal, 80(16), 1721-1737.

[6] Mahltig, B., Fiedler, D., Fischer, A., Simon, P. (2010). Antimicrobial coatings on textiles-modification of sol-gel layers with organic and inorganic biocides. Journal of SolGel Science Technology, 55, 269-277.

[7] Fu, S., Zhang, P. (2019). Surface modification of polylactic acid and poly ( $D$, L-lactide-co-glycolide) biodegradable materials via chitosan-coating treatment: $A$ new approach for developing novel antibacterial acupoint catgut embedding materials. Textile Research Journal, 89(13), 2583-2594.

[8] Mohammad, N. M., Shamim, A. A., Hridam, D., Ashraful, I., Xiaolin, S. (2018). Eco-friendly UV blocking finishes extracted from Amaranthus viridis and Solanum nigrum. Tekstilec, 61(2), 93-100.

[9] Zikeli, S. (2006). Production process of a new cellulosic fiber with antimicrobial properties. Current Problems of Dermatology, 33, 110-126.

[10] Simončič, B., Tomšič, B., Černe, L., Orel, B., Jerman, I., et al. (2012). Multifunctional water and oil repellent and antimicrobial properties of finished cotton: Influence of sol-gel finishing procedure. Journal of Sol-Gel Science Technology, 61, 340-354. 
[11] Tomšič, B., Simončič, B., Orel, B., Černe, L., Forte Tavčer, $P$., et al. (2008). Sol-gel coatings of cellulose fibers with antimicrobial and repellent properties. Journal of Sol-Gel Science Technology, 47, 44-57.

[12] Roy, S., Ghosh, S., Bhowmick, N. (2019). Mechanism of bacterial attachment on textile fibrous media. The Journal of The Textile Institute, 110(6), 916-923.

[13] Chen, Q., Ma, P., Mao, H., Xuhong, M., Gaoming, J. (2017). The effect of knitting parameter and finishing on elastic property of Pet/PBT warp knitted fabric. AUTEX Research Journal, 17(4), 350-360.

[14] Mickeviciene, A., Mikucioniene, D., Rageliene, L. (2014). Influence of raw composition of plain plated knits on their antimicrobial characteristics. Fibres \& Textiles in Eastern Europe, 22(5), 69-64.

[15] Mikucioniene, D. Arbataitis, E. (2013). Comparative analysis of the influence of bamboo and other cellulose fibres on selected structural parameters and physical properties of knitted fabrics. Fibres \& Textiles in Eastern Europe, 21(3), 76-80.
[16] Mariappan, G., Dhandapani, S. (2020). Antimicrobial activity of gloriosa superba, cyperus rotundus and pithecellobium dulce with different solvents. Fibres \& Textiles in Eastern Europe, 28, 4(142), 67-71.

[17] Zhang, Y. Y., Xu, Q. B., Fu, F. Y. (2016). Durable antimicrobial cotton textiles modified with inorganic nanoparticles. Cellulose, 23, 2791-2808.

[18] XiangDong Liu. (2018). An effect of washing on durability of hydrophobic finishes of membrane laminates. AUTEX Research Journal, 18(2), 137-142.

[19] Bivainyte, A., Mikucioniene, D. (2012). Influence of shrinkage on air and water vapour permeability of double-layered weft knitted fabrics. Materials ScienceMedziagotyra, 18(3), 271-274.

[20] Tvarijonaviciene, B., Ciukas, R., Mikucioniene, D. (2005). Influence of knitting process conditions and washing on tensile characteristics of knitted ribbon yarns. Fibres \& Textiles in Eastern Europe, 13(4), 74-77. 